\title{
DIE MODERERENDE INVLOED VAN LOOPBAANONTPLOOIING OP LOOPBAANPASSING EN GEHALTE VAN WERKLEWE
}

\author{
A.M.G. SCHREUDER \\ J. FLOWERS \\ Departement Bedryfsielkunde \\ Universiteit van Suid-Afrika
}

\begin{abstract}
The moderating influence of career progression on career fit and the quality of work life. The subject under investigation was the moderating influence of career progression on career fit and the quality of worklife of 258 employees at non-management and management level in various types of organisations [private, semistate and state]. A significant degree of fit was found among the management group, after which the differences in the quality of worklife between the fit and non-fit groups were tested. A significant difference [p < 0,01 ] was only found for the management group, with the fit group achieving a significantly higher score. The implications of these findings with regard to career planning for the individual and the organisation are discussed.
\end{abstract}

\section{OPSOMMING}

Die modererende invloed van loopbaanontplooiing op loopbaanpassing en gehalte van werklewe van 258 werknemers op nie-bestuur- en bestuursvlak in verskillende organisasietipes (privaat, semi-staat en staat) is ondersoek. ' $n$ Betekenisvolle passing is by die bestuursgroep gevind, waarna vir verskille in gehalte van werklewe tussen die passings- en nie-passingsgroep getoets is. Dit is slegs by die bestuursgroep dat ' $n$ betekenisvolle verskil $[\mathrm{p}<0,01]$ gevind is, met die passingsgroep wat 'n betekenisvolle hoër telling behaal het. Die implikasies van die bevindings ten opsigte van loopbaanbeplanning vir die individu en onderneming word bespreek.

Soos wat werknemers se loopbane ontplooi, ervaar sommiges 'n passing met hulle poste en andere nie. Die resultaat hiervan kan moontlik ' $n$ hoër of laer gehalte van werklewe wees. Die vraag ontstaan dan of loopbaanontplooiing 'n invloed op die loopbaanpassing en die gehalte van werklewe van werknemers kan hê.

Loopbaanontplooiing, kan aan die hand van verskillende loopbaanstadiums omskryf word. Volgens Levinson (1977) en Burack (1984) is loopbaanstadiums beroepsverwant en behels dit werkverwante gedrag waardeur die individu poog om sy behoeftes en waardes te bevredig. Verskillende loopbaanstadiums word onder andere deur Dalton, Thompson en Price (1977) onderskei. Gedurende stadium I werk die individu as 'n leerling onder toesig en word hy deur een of meer mentors ondersteun. Die werkinhoud is uitsluitlik geroetineerd van aard. In stadium II lewer die individu bewys van sy bevoegdheid deur' $n$ individuele bydrae te maak. Die primêre tema van hierdie stadium is onafhanklikheid en dié individu wat hierdie stadium bereik, ontwikkel 'n reputasie van 'n tegnies-bevoegde professionele persoon wat onafhanklik kan werk en betekenisvolle resultate kan lewer. In stadium III verbreed sy optrede en tree hy as mentor op vir andere. Om andere te beinvloed, leiding en ontwikkeling te bied is belangrike verantwoordelikhede van hierdie individue. Veral drie rolle word by hulle geïdentifiseer, naamlik informele mentor, die genereerder van idees en bestuurder. Die individue wat stadium IV bereik, beïnloed gewoonlik die rigting van die organisasie. Hulle is gewoonlik lynbestuurders en het 'n bepaalde invloed op die toekoms van die organisasie.

Navorsing by individue ouer as 40 jaar wat reeds stadiums III en IV bereik het, toon dat hulle oorwegend bogemiddeld presteer het, in teenstelling met dié wat slegs stadiums I en II bereik het. Die navorsers kom tot die gevolgtrekking dat om bogemiddeld te presteer, ' $n$ individu ten minste tot stadium III behoort te vorder (Dalton et al., 1977). Hiervolgens wil dit lyk asof loopbaanontplooiing, beskryf volgens bogenoemde loopbaanstadiums, prestasievlak beïnvloed. Terselfdertyd kan die vraag ontstaan tot watter mate loopbaanontplooiing ' $n$ invloed sal hê op loopbaanpassing en gehalte van werklewe as resultaat. Dit mag wees dat soos wat' $n$ individu se loopbaan vorder sekere waardes en behoeftes meer dominant raak. Volgens Fottler en Bain (1984) kan dit nuttige navorsing wees om die verband tussen loopbaanstadiums, loopbaanbehoeftes, waardes, doelwitte en gehalte van werklewe te ondersoek. Hulle noem verder dat individuele behoeftes en doelwitte op verskillende stadiums in die loopbaansiklus kan verander sodat dit wat op een stadium tevredenheid verskaf nie noodwendig op 'n ander stadium tevredenheid sal verskaf nie. Fottler en Bain (1984) noem ten slotte dat hoë werksbetrokkenheid, tevredenheid en produktiwiteit moontlik net vir daardie individue met ' $n$ passing tussen loopbaanoriëntasie, familiestadium, loopbaanstadium en die eksterne vereistes van die pos beskore is.

Individue word gedurende hulle totale lewe dikwels met loopbaankeuses gekonfronteer en Hall (1976) onderskryf dit as hy noem dat 'n loopbaankeuse nie 'n eenmalige aktiwiteit is wat in die vroeë twintigerjare plaasvind nie, maar gereeld herhaal word. Loopbaanpassing kan omskryf word as die mate waarin 'n werker se loopbaan sy belangstellings verwesenlik, sy behoeftes en waardes bevredig en hom die geleentheid bied om uitdrukking aan homself te gee.

Navorsing oor loopbaanpassing het oor die afgelope dekades nie agterweë gebly nie. Volgens Hall (1976) het navorsing getoon dat veral vier eienskappe, naamlik belangstelling, selfkonsep, persoonlikheid (byvoorbeeld behoeftes, persoonlike oriëntering, waardes) en sosiale agtergrond oorweeg kan word met betrekking tot loopbaanpassing.

Heelwat navorsing is al oor die rol van belangstelling by loopbaankeuse gedoen. Volgens Super en Bohn (1970) is (met uitsondering van intelligensie) belangstelling meer as enige ander sielkundige eienskap bestudeer. Op die gebiede van die ander eienskappe soos selfkonsep en persoonlikheidskenmerke het ook persone soos Super en Holland navorsing gedoen. Super (1957) het loopbaankeuse gesien as die implementering van die selfkonsep. Hy sien die selfkonsep as 'n algemene beskrywing van 'n persoon ten opsigte van homself met betrekking tot sy vermoëns, belangstellings, behoeftes, waardes, aspirasies, ensovoorts (Super \& Bohn, 1970).

'n Belangrike teorie met betrekking tot persoonlike oriëntasie in loopbaankeuse is deur Holland (1966) daargestel. Holland (1973) noem dat daar ' $n$ interaksie tussen die persoonlikheid van die individu en die omgewing is, sodat individue getrek word na omgewings wat ooreenstem met hulle persoonlike oriëntasies. 
Soos wat navorsers dan probeer het om met behulp van bogenoemde sielkundige veranderlikes 'n beter loopbaanpassing te verkry, word in hierdie studie ' $n$ individu se loopbaanankers - 'n konsep wat deur Schein geskep is - gebruik. Schein (1978) definieer 'n loopbaananker as 'n patroon van selfwaargeneemde talente, motiewe en waardes wat ' $n$ individu se loopbaan rig, begrens, stabiliseer en integreer. Hy sien die ontwikkeling van die loopbaananker soos volg:

"It is the process of integrating into the total concept what one sees oneself to be more or less competent at, wanting out of life, one's value systems and the kind of person one is that begins to determine the major life and occupational choices throughout adulthood" (Schein, 1978: 171).

Schein het op grond van 'n longitudinale studie (1961-1973) en navorsing daarna agt loopbaanankers geïdentifiseer. Schein (1990) beskryf hierdie ankers kortliks soos volg:

\section{-Tegniese/funksionele bevoegdheid}

As ' $n$ individu se loopbaananker die bevoegdheid in 'n sekere tegniese of funksionele area is, sal hy sy vaardighede in daardie area wil toepas asook poog om dit tot ' $n$ hoër vlak te ontwikkel.

\section{-Bestuursbekwaamheid}

'n Individu met algemene bestuursbekwaamheid as loopbaananker sal tot ' $n$ vlak in die organisasie wil vorder wat hom in staat sal stel om die pogings van andere te integreer en om die verantwoordelikheid vir die uitsette van ' $n$ afdeling te aanvaar.

\section{-Outonomie/onafhanklikheid}

Indien ' $n$ individu se loopbaananker outonomie/onafhanklikheid is, sal hy sy werk op sy eie manier wil interpreteer. Hy verwag buigsaamheid veral met betrekking tot wanneer en hoe om te werk.

\section{-Sekuriteit/stabiliteit}

Indien sekuriteit/stabiliteit 'n individu se loopbaananker is, sal hy nie werksekuriteit of dienstyd in 'n pos, of by 'n organisasie wil prysgee nie. Hierdie individu sal veral oor finansiële (byvoorbeeld pensioen en aftredeplanne) en werksekuriteit besorg wees.

\section{-Entrepreneur}

'n Individu met bogenoemde loopbaananker sal 'n eie onderneming wil ontwikkel. Hy sal graag aan die wêreld wil bewys dat hy ' $n$ onderneming, wat die resultaat van sy eie pogings is, kan skep.

\section{-Diens/toewyding aan 'n saak}

As 'n individu se loopbaananker diens/toewyding aan 'n saak is, sal hy streef na'n werk waar hy iets waardevols kan bydra, soos om die wêreld ' $n$ beter plek te maak om in te lewe, omgewingsprobleme op te los en om harmonie tussen mense te bevorder, asook om andere van hulp te wees.

\section{-Suiwer uitdaging}

'n Individu met bogenoemde loopbaananker sal poog om oplossings vir oënskynlike onoplosbare probleme te vind; oorwinnings oor moeilike kliënte te behaal en moeilike hindernisse te oorkom.

\section{-Lewenstyl}

As ' $n$ individu se loopbaananker lewenstyl is, sal hy ten alle koste 'n situasie nastreef wat hom in staat sal stel om sy persoonlike en familiebehoeftes met die vereistes van sy loopbaan te integreer.

Die verskillende loopbaanankers skep besondere behoeftes by die individu en oor die passing hiervan met die pos kan tydens die sluiting van die sielkundige kontrak onderhandel word. Navorsing het getoon dat 'n goeie sielkundige kontrak werkstevredenheid bevorder en daar nie werklik'n onderskeid tussen werkstevredenheid en gehalte van werklewe getref hoef te word nie, aangesien navorsers soos Boisvert (1977) en Coet- ser (1980) 'n hoë korrelasie daartussen gevind het (Schreuder, 1989). Dit behoort dus die gehalte van werklewe te bevorder deur die loopbaanankerbehoeftes by die sluiting van die sielkundige kontrak in aanmerking te neem.

As die definisies van Suttle (1976) en Dessler (1981) as uitgangspunt geneem word, sou ons gehalte van werklewe (GWL) vir doeleindes van hierdie studie kon definieer as die resultaat van die mate waarin voldoen word aan die loopbaanankerbehoeftes van ' $n$ individu op verskillende stadiums van loopbaanontplooiing. Dit sou beteken dat ' $n$ individu se GWL sal verbeter namate selfwaargeneemde behoeftes, waardes, motiewe en vermoëns bevredig word. Suttle (1976) definieer GWL as die mate waarin werkers in staat is om belangrike persoonlike behoeftes deur hulle ervarings by die organisasie te bevredig. Dessler (1981) noem dat GWL nie net in terme van materiële dinge gedefinieer moet word nie, maar ook in terme van selfrespek, tevredenheid, 'n geleentheid om talente te gebruik, 'n bydrae te maak en om persoonlik te groei.

'n Studie om te bepaal of loopbaanpassing en GWL gemodereer word deur loopbaanontplooiing, behoort verdere lig te werp op die verband tussen hierdie veranderlikes.

Die studie behels die volgende spesifieke doelstelling, naamlik om te bepaal of loopbaanontplooiing 'n modererende effek op loopbaanpassing en gehalte van werklewe het.

Na aanleiding van hierdie doelstelling kan die volgende hipotese geformuleer word:

-Die verband tussen loopbaanpassing en gehalte van werklewe word deur loopbaanontplooiing gemodereer.

\section{METODE}

\section{Proefgroep}

Daar is 258 werknemers, ouer as 35 jaar en verdeel in bestuur en nie-bestuur, in verskillende organisasietipes (privaat, semistaat, staat) betrek. Om die proefpersone in die hiërargiese vlakke te kon verdeel, is die Peromnes poswaarderingsmetode as riglyn gebruik en verder is gelet op salarisverskille om die proefgroep in die kategorieë bestuur en nie-bestuur te verdeel. Die rede vir die ouderdomsbeperking is gebaseer op Schein (1978) se mening dat die vroeë loopbaantydperk gesien moet word as 'n periode waartydens die persoon as gevolg van werklike ervaringe in die werksomgewing meer leer omtrent homself en sy beroep.

Tabel 1 toon die verspreiding van die totale getal proefpersone aan met betrekking tot hiërargiese vlakke.

TABEL 1

FREKWENSIETABEL VAN DIE PROEFGROEP MET BETREKKING TOT HIËRARGIESE VLAKKE

\begin{tabular}{|l|c|c|}
\hline Hiërargiese vlak & Aantal & Persentasie \\
\hline Nie-bestuur & 99 & 38,4 \\
Bestuur & 153 & 59,3 \\
Onbekend & $\frac{6}{2,3}$ \\
& 258 & $\frac{100,0}{}$ \\
\hline
\end{tabular}

Volgens hierdie tabel behoort die meeste proefpersone (59,3\%) tot die bestuursgroep.

Ander belangrike kenmerke van die proefgroep was soos volg: 62,8 persent was manlik en 75,9 persent was Afrikaanssprekend. Een en sestig persent het oor 'n naskoolse kwalifikasie beskik. Ongeveer 45 persent het geen werkverandering gedurende die afgelope tien jaar gemaak nie, en 26 persent het slegs een verandering gemaak. 


\section{MEETINSTRUMENTE}

\section{-Biografiese vraelys}

Die vraelys is saamgestel met die doel om persoonlike inligting te bekom wat nodig is om die steekproef te beskryf.

\section{-Career Orientations Inventory (COI)}

Die oorspronklike 41-item-vraelys van Schein (1985) is gebruik. Hierdie vraelys meet net sekere dimensies van 'n loopbaananker, naamlik individuele loopbaanhoudings, -waardes en -behoeftes wat as loopbaanoriëntasies gedefinieer word. Loopbaanoriëntasies vorm egter 'n sentrale gedeelte van loopbaanankers wat weer 'n samestelling van loopbaanoriëntasies en selfwaargeneemde talente is (De Long, 1982). 'n Telling word vir elke proefpersoon op elk van die agt loopbaanankers verkry.

Die geldigheid van die vraelys is deur De Long (1984), Slabbert (1987) en Boshoff, Kaplan en Kellerman (1988) ondersoek. Nadat die betroubaarheidskoëffisiënte deur De Long (1982) en Boshoff et al. (1988) bereken is, kom die navorsers tot die gevolgtrekking dat die betroubaarheid as voldoende beskou kan word om navorsing ten opsigte van sekere verbande en tendense te regverdig. Vir 'n meer volledige beskrywing van die betroubaarheid en geldigheid van die meetinstrument sien Schreuder (1989).

\section{-Pospersepsievraelys}

Hierdie vraelys is deur Schreuder (1989) ontwikkel om die proefpersone se persepsie van hulle poste met betrekking tot dieselfde faktore wat die COI meet, te bepaal. Die doel met hierdie vraelys was om die mate waarin daar 'n passing is tussen die proefpersoon se persepsie van sy pos en die kenmerke van sy dominante loopbaananker, te bepaal.

Nadat betroubaarheidskoëffisiënte deur Schreuder (1989) bereken is, kom hy tot die gevolgtrekking dat die betroubaarheid van die vraelys aanvaarbaar is. Wat die interne konsekwentheid van die vraelys betref, is redelik hoë item-faktorkorrelasies gevind.
-Organisasiediagnosevraelys (ODV)

Coster (1981) rapporteer dat die Organisasiediagnosevraelys (ODV) hoofsaaklik gebaseer is op die Michigan Organizational Assessment Package (MAOB) en die Survey of Organizations. Die ODV is spesifiek saamgestel met die doel om individuele houdings en persepsies te bepaal. Dit meet verskillende hooffaktore (bv. organisasieklimaat, werkgroepprosesse, taakeienskappe, toesighoudende leierskap, tevredenheid) en 'n aantal subfaktore in elkeen van hierdie kategorieë. Aangesien die doel van die skrywer se navorsing was om te bepaal of loopbaanontplooiing ' $n$ modererende effek op loopbaanpassing en GWL het, is ' $n$ omvattende meting van GWL noodsaaklik. Die ODV verkry metings op bogenoemde areas wat 'n betroubare meting van GWL daarstel. 'n Saamgestelde gemiddelde telling van al die faktore in die vraelys is gebruik. Vorige navorsers (Coetser, 1980; Coster, 1981; Van Pletsen, 1986 ) het die betroubaarheid en geldigheid van die vraelys bevestig.

\section{-Metode van dataversameling}

Die vraelyste is by nege organisasies in die privaat, semi-staaten staatsektore versprei. ' $n$ Dekkingsbrief wat die doel van die ondersoek bevat het en anonimiteit gewaarborg het, is by die vraelys ingesluit. Met die ondersteuning van 'n kontakpersoon by elk van die organisasies is terugvoering van 86 persent bewerkstellig. Hierdie persone was onafhanklik en nie die onmiddellike hoof van die proefpersone nie en hul funksie was hoofsaaklik om die proefpersone met die voltooiing van die vraelyste aan te moedig.

\section{RESULTATE EN BESPREKING}

Om loopbaanpassing te bepaal, is die verband tussen die dominante loopbaananker, gemeet met die COI, en die ooreenstemmende pospersepsie, soos gemeet met die pospersepsievraelys, verkry. Die finale statistiese toetsing is met behulp van die Chi-kwadraattoets gedoen. Tabel 2 toon die passing (Chi-kwadraatwaardes) tussen loopbaanankers en pospersepsies.

TABEL 2

DIE VERBAND TUSSEN LOOPBAANANKERS (COI) EN POSPERSEPSIES VIR DIE VERSKILLENDE HIËRARGIESE VLAKKE (POSPERSEPSIEVRAELYS)

\begin{tabular}{|c|c|c|}
\hline LOOPBAANANKERS/POSPERSEPSIES & NIE-BESTUUR & BESTUUR \\
\hline Tegnies/funksionele bevoegdheid & 0,107 & $7,537 * * *$ \\
\hline Bestuursbekwaamheid & - & - \\
\hline Outonomie/onafhanklikheid & - & - \\
\hline Sekuriteit/stabiliteit & $12,402^{\star * *}$ & $7,315^{\star \star *}$ \\
\hline Diens/toewyding aan 'n saak & $16,489^{\star * *}$ & $7,952^{\star * *}$ \\
\hline Suiwer Uitdaging & 0,010 & $20,991^{\star * *}$ \\
\hline Lewenstyl & $7,005^{\star * *}$ & $7,015^{\star * *}$ \\
\hline Entrepreneur & - & - \\
\hline
\end{tabular}

${ }^{*} \mathrm{p}<0,05 \quad{ }^{\star \star} \mathrm{p}<0,02 \quad{ }^{\star * \star} \mathrm{p}<0,01$

Volgens hierdie tabel is daar by die nie-bestuursgroep 'n betekenisvolle passing tussen die proefpersone met loopbaanankers van werksekuriteit, diens en lewenstyl enersyds en hul persepsie van hul posinhoud andersyds. By die proefpersone met tegnies/funksionele bevoegdheid en suiwer uitdagings as dominante ankers is geen betekenisvolle passing gevind nie. Wat bestuursbekwaamheid, outonomie en entrepreneur betref, is geen telling verkry nie, aangesien te min proefpersone hierdie ankers as dominant aangetoon het om 'n Chi-kwadraattelling te regverdig. Wat die bestuursgroep betref is daar ' $n$ betekenisvolle passing tussen al die loop- baanankers waarby 'n Chi-kwadraattelling gekry is, en die ooreenstemmende persepsies verkry.

Om te kon bepaal of loopbaanpassing gehalte van werklewe beïnvloed, is die verskille tussen die GWL-tellings van dié proefpersone met ' $n$ passing tussen loopbaananker en pospersepsie (passingsgroep) en dié proefpersone met nie 'n sodanige passing nie (nie-passingsgroep) bereken. Die t-toetse is gebruik om te bepaal of daar beduidende verskille is. Tabel 3 toon die gemiddelde GWL-tellings van die passings- en niepassingsgroep. 
TABEL 3

DIE GEMIDDELDE GWL-TELLINGS VAN DIE PASSINGS- EN NIE-PASSINGSGROEP TEN OPSIGTE VAN LOOPBAANANKERS EN POSPERSEPSIES VIR DIE VERSKILLENDE HIËRARGIESE VLAKKE

\begin{tabular}{|c|c|c|c|c|c|c|c|c|}
\hline & \multicolumn{3}{|c|}{ PASSINGSGROEP } & \multicolumn{3}{|c|}{ NIE-PASSINGSGROEP } & \multirow[b]{2}{*}{ F-WAARDE } & \multirow[b]{2}{*}{ t-WAARDE } \\
\hline HIËRARGIESE VLAK & $\mathrm{N}$ & $\begin{array}{c}\bar{X} \text {-GWL } \\
\text { TELLING }\end{array}$ & S & $\mathrm{N}$ & $\begin{array}{l}\bar{X} \text {-GWL } \\
\text { TELLING }\end{array}$ & S & & \\
\hline NIE-BESTUUR & 74 & 3,6440 & 0,5386 & 26 & 3,6278 & 0,4847 & 1,53 & 0,14 \\
\hline BESTUUR & 79 & 3,7998 & 0,4747 & 74 & 3,5975 & 0,4117 & 0,45 & $2,82^{\star \star \star}$ \\
\hline
\end{tabular}

${ }^{*} \mathrm{p}<0,05 \quad{ }^{* *} \mathrm{p}<0,02 \quad{ }^{* *} \mathrm{p}<0,01$

By die nie-bestuursgroep is geen betekenisvolle verskil tussen die twee passingsgroepe gevind nie. Dit wil dus voorkom asof GWL nie deur loopbaanpassing op hierdie vlak beïnvloed word nie. By die bestuursgroep verskil die twee groepe betekenisvol op die 1 persent peil, met die passingsgroep wat 'n betekenisvolle hoër telling behaal het. Hiervolgens wil dit lyk asof GWL wel deur loopbaanpassing op hierdie vlak beïnvloed word.

Volgens bogenoemde resultate word die verband tussen loopbaanpassing en GWL deur loopbaanontplooiing gemodereer. Die hipotese word dus aanvaar.

\section{GEVOLGTREKKING}

Die resultate van hierdie studie dui daarop dat die werkers wat loopbaanstadiums III en IV, soos beskryf volgens Dalton et al. (1977) bereik, 'n beter loopbaanpassing en 'n hoër GWL ervaar. Om dus 'n beter loopbaanpassing en 'n hoër GWL te ervaar moet loopbaanstadium III ten minste bereik word. Individue verkry gedurende loopbaanontplooiing moontlik meer duidelikheid oor hulle behoeftes en waardes wat hulle in staat stel om beter loopbaankeuses ooreenkomstig hulle eie voorkeure te kan maak. Derhalwe wil dit voorkom asof loopbaanankers al hoe belangriker raak met loopbaanontplooiing en kan dus nuttig saam met sielkundige toetse, waarvan die voorspellingsgeldigheid dikwels ' $n$ probleem is, by loopbaanpassing gebruik word.

\section{BRONNELYS}

Boshoff, A.B., Kaplan, R.A. \& Kellerman, A.M. (1988). The career anchors of members of fourteen professions in South Africa. Ongepubliseerde navorsing, Universiteit van Pretoria, Pretoria.

Burack, E.H. (1984). The sphinx riddle: Life and career cycles. Training and Development Journal, 38(4), 52-61.

Coetser, R. (1980). Individuele werkverwagtings as maatstaf vir die bepaling van die gehalte van werklewe vir programmeerders. Ongepubliseerde M.Com.-verhandeling, Universiteit van Suid-Afrika, Pretoria.

Coster, E.A. (1981). Organizational development: The implementation and evaluation of a survey-guided feedback intervention. Ongepubliseerde M.Com.-verhandeling, Universiteit van Suid-Afrika, Pretoria.

Dalton, G.W., Thomspon, P.H. \& Price, R.L. (1977). The four stages of professional careers: A new look at performance by professionals. Organizational Dynamics, 6(1), 19-42.

De Long, T.J. (1982). Reexamining the career anchor model. Personnel, 59(3), 50-61.

De Long, T.J. (1984). A comparison of the career orientations of rural and urban educators. Educational Review, 36(1), 67-74.

Dessler, G. (1981). Personnel management. Reston, VA: Reston Publishing Company.

Fottler, M.D. \& Bain, T. (1984). Realism of occupational choice among high school seniors: implications for quality of work life. Journal of Occupational Behaviour, 5(4), 237-251.

Hall, D.T. (1976). Careers in organizations. California: Goodyear Publishing Company.
Holland, J.L. (1966). The psychology of vocational choice. Massachusetts: Blaisdeel Publishing Co.

Holland, J.L. (1973). Making vocational choices: a theory of careers. Englewood Cliffs, New Jersey: Prentice-Hall Inc.

Levinson, D.J. (1977). The mid-life transition: A period in psychosocial development. Psychiatry, 40(1), 99-112.

Schein, E.H. (1978). Career dynamics: matching individual and organizational needs. Phillippines: Addison Wesley Publishing Co.

Schein, E.H. (1985). Career anchors: discover your real values. San Diego: University Associates.

Schein, E.H. (1990). Career anchors: discover your real values. San Diego: University Associates.

Schreuder, A.M.G. (1989). Die verwantskap tussen loopbaananker, beroepstipe, organisasietipe en gehalte van werklewe. Ongepubliseerde D.Admin.-proefskrif, Universiteit van SuidAfrika, Pretoria.

Slabbert, I. (1987). An evaluation of the management training and career anchors of $M B A / M B L$ graduates. Pretoria: Human Sciences Research Council.

Super, D.E. \& Bohn, M.J. (1970). Occupational psychology. California: Wadsworth Publishing Company.

Super, D.E. (1957). The psychology of careers. New York: Harper \& Row Publishers.

Suttle, J.L. (1976). Improving life at work - problems and perspectives. In: Improving life at work - behavioral sciences approaches to organizational change edited by J.R. Hackman \& J.L. Suttle, California: Goodyear Publishing Co.

Van Pletsen, F. (1986). Die interafhanklikheid van gehalte van werklewe, werkwaardes en werkverwagtings. Ongepubliseerde D.B.A.-proefskrif, Universiteit van Pretoria, Pretoria. 